\title{
Economic evaluation of patient costs associated with tuberculosis diagnosis and care in Solomon Islands
}

Kerri Viney ${ }^{1,2,3^{*}+}$ D, Noel Itogo ${ }^{4,5 \dagger}$, Takuya Yamanaka ${ }^{6,7}$, Ridha Jebeniani ${ }^{8}$, Anupama Hazarika ${ }^{5}$, Fukushi Morishita ${ }^{9}$, Nobuyuki Nishikiori ${ }^{2}$ and Susana Vaz Nery ${ }^{1,10}$

\begin{abstract}
Background: Tuberculosis (TB) care can be costly for patients and their families. The End TB Strategy includes a target that zero TB affected households should experience catastrophic costs associated with TB care. Costs are catastrophic when a patient spends $20 \%$ or more of their annual household income on their TB diagnosis and care. In Solomon Islands the costs of TB care are unknown. The aim of this study was to determine the costs of TB diagnosis and care, the types of costs and the proportion of patients with catastrophic costs.

Methods: This was a nationally representative cross-sectional survey of TB patients carried out between 2017 and 2019. Patients were recruited from health care facilities, from all ten provinces in Solomon Islands. During an interview they were asked about the costs of TB diagnosis and care. These data were analysed using descriptive statistics to describe the costs overall and the proportions of different types of costs. The proportion of patients with catastrophic costs was calculated and a multivariate logistic regression was undertaken to determine factors associated with catastrophic costs.

Results: One hundred and eighty-three TB patients participated in the survey. They spent a mean of 716 USD (inter quartile range: 348-1217 USD) on their TB diagnosis and care. Overall, $62.1 \%$ of costs were attributable to nonmedical costs, while income loss and medical costs comprised 28.5 and $9.4 \%$, respectively. Overall, $19.7 \%(n=36)$ of patients used savings, borrowed money, or sold assets as a financial coping mechanism. Three patients (1.6\%) had health insurance. A total of 92.3\% (95\% Cl: 88.5-96.2) experienced catastrophic costs, using the output approach. Being in the first, second or third poorest wealth quintile was significantly associated with catastrophic costs (adjusted odds ratio: 67.3, 95\% Cl: 15.86-489.74\%, $p<0.001$ ).

Conclusion: The costs of TB care are catastrophic for almost all patients in Solomon Islands. The provision of TB specific social and financial protection measures from the National TB and Leprosy Programme may be needed in the short term to ameliorate these costs. In the longer term, advancement of universal health coverage and other social and financial protection measures should be pursued.
\end{abstract}

Keywords: Tuberculosis, Costs, Solomon Islands, Economic impact, Health care access

\footnotetext{
*Correspondence: vineyk@who.int

${ }^{\dagger}$ Kerri Viney and Noel Itogo are Joint first authors.

${ }^{1}$ Research School of Population Health, Australian National University, Canberra, Australia

${ }^{2}$ Global TB Programme, World Health Organization Headquarters, Geneva, Switzerland

Full list of author information is available at the end of the article
}

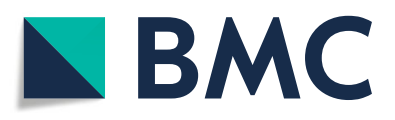

(c) World Health Organization 2021, corrected publication 2021. Open Access This is an open access article distributed under the terms of the Creative Commons Attribution IGO License (http://creativecommons.org/licenses/by/3.0/igo/legalcode), which permits unrestricted use, distribution and reproduction in any medium, provided you give appropriate credit to the original author(s) and the source, provide a link to the Creative Commons license, and indicate if changes were made. In any reproduction of this article there should not be any suggestion that WHO or this article endorse any specifc Organization or products. The use of the WHO logo is not permitted. 


\section{Background}

The costs of tuberculosis (TB) diagnosis and care are thought to be a significant impediment to accessing health care for patients, and to attaining national and global targets of reductions in TB incidence and mortality for national TB programmes [1]. Previous studies have documented that TB patients often incur large costs related to their illness, as well as seeking and receiving health care $[2,3]$. Such costs can create barriers to health care access and treatment adherence, which can affect health outcomes and increase the risk of TB transmission. These costs can also be detrimental to the economic situation of households as TB predominantly affects people of working age. By way of example, in low-and middle-income countries, TB patients face costs that on average amount to half of their annual income [2]. Lost income is often the dominant contributor to economic hardship; however out-of-pocket medical expenditures are also important [4-6]. In addition, costs for travel, food and relocation during health seeking are also significant, given the often long health seeking period and the six-month to two-year period of TB treatment that is the internationally accepted standard for treatment to be effective [2]. In fact, a previous systematic review determined that these costs are equivalent to $58 \%$ of annual individual income and 39\% of annual household income, worse for people who were already poor or who had multidrug-resistant (MDR)-TB [2].

The costs of TB diagnosis and care can be estimated through national TB patient cost surveys using a methodology designed by the World Health Organization (WHO) [7]. Using this method, measurement of a range of patient costs due to TB help to identify areas for improvement in TB service delivery and financing, and contribute to the measurement of the End TB Strategy indicator for the target that zero TB affected households should experience catastrophic costs related to TB, to be attained by the year 2020 [1]. Costs are said to be "catastrophic" when spending on TB is equal to or greater than $20 \%$ of the TB patients' annual household income [1]. The results of such surveys are important to assess the magnitude of patient costs and identify the main categories of costs, which can then be used to monitor financial barriers to accessing and adhering to TB services and inform related health and social policy changes to improve TB care [8].

Solomon Islands is a medium burden TB country. It reports approximately $400 \mathrm{~TB}$ case notifications per year, resulting in a TB case notification rate of 62 cases per 100,000 population $[9,10]$. A joint programme review of the National TB and Leprosy Programme (NTLP) in 2019 identified multiple barriers for patients in accessing TB services along their care pathways. TB patients often present late for a TB diagnosis, mainly due to a lack of awareness about $\mathrm{TB}$, and difficult access to health facilities due to the country's geography and lack of public transport [11]. Health centres also lack laboratory and human resource capacity to diagnose and initiate TB treatment, so they often refer patients to a provincial hospital [11]. If the patient is diagnosed with TB, historically they have been hospitalized for two months and then after this, they are discharged and receive treatment closer to their home [11]. However, the real costs of TB care are unknown in Solomon Islands.

Therefore, this study aimed to conduct a baseline assessment of the economic burden of TB on patients and their households in Solomon Islands, using the WHO recommended national TB patient survey methodology, something that was also recommended during the 2019 programme review [11]. The specific aims were to determine the financial burden of TB for patients in Solomon Islands and to inform policies to mitigate costs and improve access to TB care.

\section{Methods}

\section{Setting}

Solomon Islands is comprised of over 900 islands and is located in the Pacific Ocean [12]. It has a population of approximately 640,000 people, of whom $80 \%$ live in rural areas $[12,13]$. It is a lower middle income country [9] where $12.7 \%$ of the population live below the national poverty line [14]. Health care in Solomon Islands is largely provided by the public sector and out-of-pocket spending on health is low [15]. However, non-medical expenditures, particularly for transportation to access health care, are reported to be high $[16,17]$. The Solomon Islands NTLP is based in Honiara (the capital). Then, in all ten provinces, there is a designated health facility or hospital that serves as a TB Directly Observed Treatment Short-course (DOTS) centre, which is staffed by a Provincial Tuberculosis and Leprosy Coordinator. It provides TB services and serves as a TB Basic Management Unit for that province. The country has been implementing the World Health Organization (WHO) recommended strategy for controlling $\mathrm{TB}$, which evolved from the DOTS strategy, the Stop TB strategy and currently the End TB Strategy. For the past decades, the NTLP has made good progress against a number of programmatic indicators [11]. For example, the treatment coverage and treatment success rates in 2017 were 80 and $92 \%$ respectively and the proportion of TB patients who were bacteriologically confirmed in 2018 was 65\% [11]. However, various challenges remain; including; access barriers, limited implementation planning across all levels of the health system, resource constraints which limit outreach services and inconsistent use of preventive therapy in eligible risk groups [11]. 


\section{Study design}

This was cross-sectional survey of TB patients including all ten DOTS centres offering TB treatment in the country, and therefore a nationally representative study that aimed to assess the costs associated with TB diagnosis and care.

\section{Sampling approach and study population}

The sample size was estimated at 228 patients. This figure was based on the number of DOTS centres offering TB treatment $(n=10)$, and the number of patients diagnosed in Solomon Islands per year (at the time of protocol development in 2016, this was $n=360$ ), assuming a level of $30 \%$ catastrophic costs and a $5 \%$ nonparticipation rate. At the time, $30 \%$ was deemed a reasonable estimate given the pre existing knowledge on this topic [2]. The study population consisted of all diagnosed TB patients (of all ages and with all types of TB) who had received TB treatment for at least two weeks whether they were in the intensive phase or the continuation phase, from the selected DOTS centres.

\section{Questionnaire}

The WHO have developed a standardised, structured questionnaire for TB patient cost surveys which was adapted to the Solomon Islands context (Additional file 1). The questionnaire contained information on clinical parameters; demographic variables and household composition; socioeconomic variables; health care utilisation; time spent seeking and receiving care; direct medical, direct non-medical and indirect costs; household and individual income; household assets; financial and social coping mechanisms and the perceived impacts of costs. The questionnaire contained closed and open-ended questions. It was pilot tested and further refined after a two-day national training on data collection methods and interview techniques. The questionnaire was uploaded into Open Data Kit collect within the Ona platform (https://ona.io/home/), and was designed with built-in options and skips to promote accurate data collection.

\section{Patient interviews}

Interviewers were trained Provincial TB and Leprosy Co-ordinators or other NTLP staff (i.e. health care workers). They approached TB patients to be involved in the study as they attended clinic visits. Interviews took place at the clinic or during follow up home visits in a separate space or outside, to allow for privacy and to ensure optimal infection control practices. All patients interviewed were on effective treatment for more than two weeks prior to the interview, and as such the infection risk was minimal. Interviewers read the questions to TB patients in Solomon Islands Pigin (the lingua franca in Solomon Islands), and recorded responses directly into a tablet. For children aged under 18 years, an accompanying parent or guardian answered the questions. The interviews took 60-90 min to complete.

\section{Data collection and management}

Data were collected between 2017 and 2019. Once the interview was finished, interviewers submitted the data in the Ona platform; data were then sent directly to a password protected server, also in Ona. A small number of questionnaires were completed on a paper version (a direct replication of the electronic version); these were then sent to the NTLP Co-ordinator who entered them into Ona. During the period of data collection, remote checks of the data were undertaken by the survey investigators; any obvious or repetitive errors were fed back to the NTLP Co-ordinator and the interviewers. Then, in December 2019, during a Provincial TB and Leprosy Co-ordinator training, each record was checked by an experienced external consultant and any errors were corrected ( $\mathrm{T}$ Yamanaka, personal communication, July 2020).

\section{Definitions and data analysis}

Direct medical costs were defined as "out-of-pocket payments made by TB-affected patients or their guardians for medical services (i.e. consultations, tests, medicines, other medical procedures), net of any reimbursements" while direct non-medical costs were defined as "out-ofpocket payments made by TB-affected patients or guardians related to transportation, accommodation, food, nutritional supplements", net of any reimbursements [7]. Indirect costs were "productivity and economic costs of a TB patient or someone in their household incurred as a result of TB health care visits and hospitalization during the TB episode." [7]. Catastrophic costs were defined as the sum of direct medical, direct non-medical and indirect costs, net of any welfare payment that exceeded $20 \%$ of the household's income [1].

Annual household income was estimated using two approaches. An adjusted approach was added as Solomon Islands has a large informal and cash based economy [7]. Using the output approach, indirect costs were measured using "self-reported household income at three points in time (prior to the onset of TB symptoms, at the time of diagnosis and during the current treatment phase) to estimate income change before and during the TB episode." [7]. For households without income information, it was imputed using a regression model based on household assets information. Using a second (adjusted) approach, household income was adjusted to account for the proportion of the population with noncash based income, using the results from the most recent Solomon Islands Household Income Expenditure 
Survey (HIES); completed in 2013 [18]. The results of the HIES revealed that cash-based income accounted for $63 \%$ of total annual income, and this proportion was considerably lower in rural areas and for poor households [18]. Self-reported household income was then adjusted using the following method:

1. the reported household income was assumed to be "cash-based" income;

2. for those who did not have household income information, it was imputed based on household assets;

3. HIES income decile groups were applied to reported household income (Supplementary Table 1);

4. household cash-based income was divided by the proportion of households with cash- based income observed in the HIES (by decile).

All analyses were carried out using the statistical software package $\mathrm{R}$ 4.0.2 (CRAN:Comprehensive RArchive Network at https://cran.r-project.org/). R scripts prepared by the Global TB Programme, WHO, were used as the basis for analyses with modifications for the analytical approach. The study population was described using descriptive statistics with mean or median values used as appropriate. Median medical, non-medical costs and indirect costs, before TB treatment started and during TB treatment were calculated. Medical, non-medical and indirect costs as a proportion of all costs were also determined, as was the proportion of $\mathrm{TB}$ patients who incurred catastrophic costs. To estimate the costs of TB care for the entire period of $\mathrm{TB}$ diagnosis and care, we imputed costs based on data from patients in a certain treatment phase (i.e. intensive or continuation phase). This is the approach recommended by WHO, where missing cost data for a particular phase of TB treatment are replaced by the median values obtained from other survey participants in the same phase. $\mathrm{Pa}$ tients with pulmonary $\mathrm{TB}$ and extra-pulmonary $\mathrm{TB}$ were compared using the chi-square test for categorical data and the Welsh T-test or two-sample Wilcoxon rank-sum test for continuous data. Finally, a stepwise multivariate regression analysis was undertaken to determine which binary variables were independently associated with catastrophic costs. We used the adjusted household income for the regression analysis, as the proportion of patients with catastrophic costs was lower (i.e. it was more conservative). Adjusted odds ratios with their associated 95\% confidence intervals (CIs) and $p$ values were presented. Measures of association were considered significant at the $5 \%$ significance level.

\section{Results}

\section{Demographic and clinical characteristics}

A total of 183 TB patients participated in the survey; 147 (80.3\%) had pulmonary TB (PTB) and 36 (19.7\%) had extra-pulmonary TB (EPTB) (Table 1). There were no statistically significant differences between patients with EPTB and PTB except for the year of TB registration and province of residence ( $p=0.036$ and 0.028 , respectively). Ninety-two (50.3\%) patients were male and the mean age was 32.8 years (95\% CI: 30.3-35.2). Only 23 (12.6\%) reported being employed before their TB diagnosis and overall, the median monthly household income was USD 22.2 (inter-quartile range (IQR) 12.391.1) or 180.0 Solomon Island dollars (IQR 100.0$740.0)$ ). All patients were being treated for drug susceptible TB, 97 (53.0\%) were in the intensive phase, and 95 (51.9\%) were hospitalized at the time of interview (Table 2). The only statistically significant differences when comparing the clinical characteristics of patients with EPTB and PTB were the proportion of patients who were bacteriologically confirmed $(13.9 \%$ vs $78.9 \%$, $p<0.001$, for ЕРTB and PTB respectively) and the mean duration of the intensive phase (2.3 months vs. 2.1 months, $p=0.048$, for EPTB and PTB, respectively). Fifty-three percent $(n=44)$ patients reported a diagnostic delay (defined as an interval between onset of symptoms and a TB diagnosis of four weeks or more) (Supplementary Table 2).

\section{Time lost for care seeking and treatment}

Patients lost a mean of 354.4 working hours (95\%CI: $287.3,421.4)$. Additionally, the household lost a mean of 105.7 working hours $(95 \% \mathrm{CI}$ : 33.1, 178.3) for TB care seeking and treatment (Table 3). Patients with EPTB lost more time compared to PTB patients $(490.7 \mathrm{~h}$ for EPTB and $321.0 \mathrm{~h}$ for PTB, $p=0.047$ ) due to a significantly longer time for hospitalization $(463.7 \mathrm{~h}$ for EРTB versus $292.3 \mathrm{~h}$ for PTB, $p=0.041$ ).

\section{Estimated total costs incurred by TB patients and their households and proportion of TB-affected households experiencing catastrophic costs (using the output method)}

The median cost of a TB diagnosis and care was USD 716 (IQR: $349-1247$ ), equivalent to 8.8 times the reported monthly household income (Table 4). The costs were driven by direct non-medical costs (62.1\%), income loss (28.5\%), and direct medical costs (9.4\%) (Fig. 1). Costs for nutritional supplements other than the patients' regular diet accounted for the highest proportion of direct non-medical costs $(27.3 \%$ of all costs) followed by food costs (12.1\%), travel costs (11.9\%) and accommodation (8.3\%). Direct medical costs were predominantly incurred after diagnosis and were driven by costs 
Table 1 Socio-demographic characteristics of patients who participated in the Solomon Islands national tuberculosis patient cost survey: 2017-2019

\begin{tabular}{|c|c|c|c|c|}
\hline Socio-demographic characteristics & $\begin{array}{l}\text { Extra-pulmonary TB } \\
N=36 \\
\mathrm{n}(\%)\end{array}$ & $\begin{array}{l}\text { Pulmonary TB } \\
N=147 \\
\mathrm{n}(\%)\end{array}$ & $\begin{array}{l}\text { All patients } \\
N=183 \\
\mathrm{n}(\%)\end{array}$ & $p$ value* \\
\hline \multicolumn{5}{|l|}{ Age group (years) } \\
\hline $0-14$ & $3(8.3)$ & $18(12.2)$ & $21(11.5)$ & \multirow[t]{7}{*}{0.964} \\
\hline $15-24$ & $10(27.8)$ & $31(21.1)$ & $41(22.4)$ & \\
\hline $25-34$ & $8(22.2)$ & $32(21.8)$ & $40(21.9)$ & \\
\hline $35-44$ & $8(22.2)$ & $30(20.4)$ & $38(20.8)$ & \\
\hline $45-54$ & $4(11.1)$ & $20(13.6)$ & $24(13.1)$ & \\
\hline $55-64$ & $2(5.6)$ & $9(6.1)$ & $11(6.0)$ & \\
\hline $65+$ & $1(2.8)$ & $7(4.8)$ & $8(4.4)$ & \\
\hline Mean $(95 \% \mathrm{Cl})$ & $31.8(26.4,37.2)$ & $33.0(30.2,35.8)$ & $32.8(30.3,35.2)$ & 0.700 \\
\hline \multicolumn{5}{|l|}{ Sex } \\
\hline Female & 19 (52.8) & $72(49.0)$ & $91(49.7)$ & \multirow[t]{2}{*}{0.683} \\
\hline Male & $17(47.2)$ & $75(51.0)$ & $92(50.3)$ & \\
\hline \multicolumn{5}{|l|}{ Year of TB registration } \\
\hline 2017 & $0(0.0)$ & $13(8.8)$ & $13(7.1)$ & \multirow[t]{3}{*}{0.036} \\
\hline 2018 & $20(55.6)$ & $95(64.6)$ & $115(62.8)$ & \\
\hline 2019 & $16(44.4)$ & $39(26.5)$ & $55(30.1)$ & \\
\hline \multicolumn{5}{|l|}{ Province } \\
\hline Central & $1(2.8)$ & $4(2.7)$ & $5(2.7)$ & \multirow[t]{9}{*}{0.028} \\
\hline Choiseul & $0(0.0)$ & $5(3.4)$ & $5(2.7)$ & \\
\hline Guadalcanal & $7(19.4)$ & $15(10.2)$ & $22(12.0)$ & \\
\hline Honiara City & $16(44.4)$ & $35(23.8)$ & $51(27.9)$ & \\
\hline Makira & $2(5.6)$ & $21(14.3)$ & $23(12.6)$ & \\
\hline Malaita & $10(27.8)$ & $36(24.5)$ & $46(25.1)$ & \\
\hline Temotu & $0(0.0)$ & $11(7.5)$ & $11(6.0)$ & \\
\hline Western & $0(0.0)$ & 19 (12.9) & $19(10.4)$ & \\
\hline Ysabel & $0(0.0)$ & $1(0.7)$ & $1(0.5)$ & \\
\hline \multicolumn{5}{|l|}{ Insurance status } \\
\hline No insurance & $36(100.0)$ & $144(98.0)$ & $180(98.4)$ & \multirow[t]{2}{*}{0.387} \\
\hline With insurance & $0(0.0)$ & $3(2.0)$ & $3(1.6)$ & \\
\hline \multicolumn{5}{|l|}{ Education level } \\
\hline No education & $9(25.7)$ & $23(15.6)$ & $32(17.6)$ & \multirow[t]{4}{*}{0.560} \\
\hline Pre- or primary school & $16(45.7)$ & $75(51.0)$ & $91(50.0)$ & \\
\hline Secondary school & $8(22.9)$ & $41(27.9)$ & 49 (26.9) & \\
\hline University, vocational or other & $2(5.7)$ & $8(5.4)$ & $10(5.5)$ & \\
\hline \multicolumn{5}{|l|}{ Employment status, pre-disease } \\
\hline Employed & $7(19.4)$ & $16(10.9)$ & $23(12.6)$ & \multirow[t]{3}{*}{0.265} \\
\hline Unemployed & $14(38.9)$ & $75(51.0)$ & $89(48.6)$ & \\
\hline Student, retired, household work or other & $15(41.7)$ & $56(38.1)$ & $71(38.8)$ & \\
\hline \multicolumn{5}{|l|}{ Household size } \\
\hline Mean $(95 \% \mathrm{Cl})$ & $6.7(5.7,7.7)$ & $6.7(6.3,7.2)$ & $6.7(6.3,7.1)$ & 0.970 \\
\hline \multicolumn{5}{|c|}{ Reported household income, monthly, pre-disease, monthly } \\
\hline Median (IQR) & $12.3(0.0,87.4)$ & $24.6(12.3,92.4)$ & $22.2(12.3,91.1)$ & 0.252 \\
\hline
\end{tabular}


Table 1 Socio-demographic characteristics of patients who participated in the Solomon Islands national tuberculosis patient cost survey: 2017-2019 (Continued)

\begin{tabular}{llll}
\hline Socio-demographic characteristics & $\begin{array}{l}\text { Extra-pulmonary TB } \\
\mathbf{N = 3 6} \\
\mathbf{n}(\%)\end{array}$ & $\begin{array}{l}\text { Pulmonary TB } \\
\mathbf{N = 1 4 7} \\
\mathbf{n}(\%)\end{array}$ & $\begin{array}{l}\text { All patients } \\
\mathbf{N = 1 8 3} \\
\mathbf{n}(\%)\end{array}$ \\
\hline $\begin{array}{l}\text { TB patient was main income earner } \\
\text { Yes }\end{array}$ & $1(2.8)$ & $8(5.4)$ & $9(4.9)$ \\
No & $14(38.9)$ & $66(44.9)$ & $80(43.7)$ \\
Equal contributor & $13(36.1)$ & $40(27.2)$ & $53(29.0)$ \\
Not an income earner & $8(22.2)$ & $33(22.4)$ & $41(22.4)$ \\
\hline
\end{tabular}

Abbreviations: Cl Confidence interval; IQR Inter quartile range; TB Tuberculosis.* $P$ values compare the proportions of patients with the characteristic of interest, in the pulmonary and extra-pulmonary groups

associated with hospitalization. There were statistically significant differences observed in the costs of direct medical costs before diagnosis $(p=0.033)$, transport during TB treatment $(p<0.001)$, food during TB treatment $(p=0.039)$, total direct non-medical costs $(p=0.044)$ and direct medical costs $(p=0.042)$ when comparing patients with EPTB and PTB. In all cases, the costs were higher for patients with ЕРTB, compared to patients with PTB.

The proportion of TB-affected households experiencing catastrophic costs was 92.3\% (95\%CI: 88.5-96.2\%) using the output approach. When only direct costs were included (which accounted for $71.5 \%$ of total TB patient costs overall), $81.4 \%$ of TB-affected households incurred catastrophic costs. When the catastrophic costs threshold was changed (in a range from 10 to $60 \%$, using the output approach), the proportion of patients incurring catastrophic costs ranged from 78.1 to $95.1 \%$ (Supplementary Table 3).

Influence of adjustment for cash-based household income on estimated total costs incurred by TB patients and their households and proportion of TB-affected households experiencing catastrophic costs

We also estimated income and therefore the proportion of patients with catastrophic costs taking into account the reported household income observed in this survey and the household income decile recorded in the Solomon Islands HIES. Using this approach 171 (93.4\%) patients were classified in the poorest wealth decile. The remainder were categorized as being in the second to fourth wealth decile groups, with no households classified in the fifth to tenth deciles (Supplementary Table 4). The adjusted mean monthly household income was then estimated at USD 367.9 (95\%CI: 298.6-437.3) and the median cost of TB care was USD 1193 (IQR: 532-2346), with a corresponding increase in income loss to USD 312 (IQR: 0-1247). This was equivalent to 3.2 times the adjusted monthly household income and 14.6 times the reported median monthly household income (based on the survey responses). Costs were higher among patients with EPTB (USD 1202; IQR: 727-2777) than patients with PTB (USD 1107; IQR: 521-2241, $p=0.195$ ) (Supplementary Table 5). Using the adjusted household income, the proportion of direct non-medical costs was $48.1 \%$ (versus $62.1 \%$ using the output method), while the proportion of income loss increased from 28.5 to $45.4 \%$, and the proportion of direct medical costs was $6.4 \%$, compared 9.4\% using the output method. Then, the proportion of TB-affected households facing catastrophic costs was $82.0 \%$ (95\%CI: 76.3-87.6\%; 86.1\% (95\%CI: 74.2-98.0\%) for patients with EPTB, and $81.0 \%$ (95\%CI: 74.5-87.4\%) for patients with PTB).

\section{Factors associated with catastrophic costs due to TB}

In multivariate analyses, where we used the adjusted household income, being poorer was significantly associated with having catastrophic costs due to TB (Table 5). 96.9\% of TB affected households classified as being in the first (poorest), second or third poorest quintiles faced catastrophic costs, and they had 67.3 times higher odds of experiencing catastrophic costs compared with the wealthiest households (95\% CI: 15.86-489.74, $p<$ $0.001)$.

\section{Reported coping mechanism and social consequences}

Overall, 19.7\% $(n=36)$ of TB-affected households used their savings, borrowed money, or sold their assets as financial coping mechanisms (Table 6). One quarter (24.6\%, $n=45)$ experienced food insecurity, 21.3\% ( $n=$ 39 ) interrupted schooling, and $8.2 \%$ lost their job $(n=$ 15). In terms of perceived financial impact due to $T B$, $83.7 \%(n=153)$ reported that TB had a moderate to very serious financial impact on their households (moderate: $37.2 \%$, serious: $35.0 \%$, very serious: $11.5 \%$; these categories of severity were self reported by patients). Only $4.9 \%$ $(n=9)$ received social support either from family or relatives $(n=7)$ or from the Parliament $(n=2)$. In addition, $36.1 \%(n=66)$ received vouchers in the form of food support $(n=63)$, a travel voucher $(n=1)$, or via an unknown source $(n=2)$. There were no statistically significant differences observed between patients with EPTB 
Table 2 Clinical information of patients who participated in the Solomon Islands national tuberculosis patient cost survey: 20172019

\begin{tabular}{|c|c|c|c|c|}
\hline Clinical characteristics & $\begin{array}{l}\text { Extra-pulmonary TB } \\
N=36 \\
\mathrm{n}(\%)\end{array}$ & $\begin{array}{l}\text { Pulmonary TB } \\
N=147 \\
\mathrm{n}(\%)\end{array}$ & $\begin{array}{l}\text { All patients } \\
N=183 \\
\mathrm{n}(\%)\end{array}$ & $p$ value* \\
\hline \multicolumn{5}{|l|}{ Treatment registration group } \\
\hline New & $34(94.4)$ & $136(92.5)$ & $170(92.9)$ & \multirow[t]{3}{*}{0.917} \\
\hline Relapse & $1(2.8)$ & $5(3.4)$ & $6(3.3)$ & \\
\hline Retreatment excluding relapse & $1(2.8)$ & $6(4.1)$ & $7(3.8)$ & \\
\hline \multicolumn{5}{|l|}{ Drug resistance status } \\
\hline Drug susceptible-TB & $36(100.0)$ & $147(100.0)$ & $183(100.0)$ & - \\
\hline \multicolumn{5}{|l|}{ HIV status } \\
\hline Negative & $24(66.7)$ & $92(62.6)$ & $116(63.4)$ & \multirow[t]{3}{*}{0.813} \\
\hline Positive & $0(0.0)$ & $1(0.7)$ & $1(0.5)$ & \\
\hline Unknown & $12(33.3)$ & $54(36.7)$ & $66(36.1)$ & \\
\hline \multicolumn{5}{|l|}{ Drug susceptibility testing conducted } \\
\hline DST done & $0(0.0)$ & $2(1.4)$ & $2(1.1)$ & \multirow[t]{2}{*}{0.482} \\
\hline DST not done & $36(100.0)$ & $145(98.6)$ & $181(98.9)$ & \\
\hline \multicolumn{5}{|l|}{ Mode of TB diagnosis } \\
\hline Bacteriologically confirmed & $5(13.9)$ & $116(78.9)$ & $121(66.1)$ & \multirow[t]{2}{*}{$<0.001$} \\
\hline Clinically diagnosed & $31(86.1)$ & $31(21.1)$ & $62(33.9)$ & \\
\hline \multicolumn{5}{|l|}{ Treatment phase } \\
\hline Intensive phase & $21(58.3)$ & $76(51.7)$ & $97(53.0)$ & \multirow[t]{2}{*}{0.475} \\
\hline Continuation phase & $15(41.7)$ & $71(48.3)$ & $86(47.0)$ & \\
\hline Duration of intensive phase (months, mean $(95 \% \mathrm{CI})$ ) & $2.3(2.0,2.5)$ & $2.1(2.0,2.2)$ & $2.1(2.1,2.2)$ & 0.048 \\
\hline Duration of continuation phase (months, mean $(95 \% \mathrm{CI})$ ) & $5.1(4.8,5.5)$ & $4.8(4.6,5.0)$ & $4.9(4.7,5.0)$ & 0.054 \\
\hline \multicolumn{5}{|l|}{ Treatment facility } \\
\hline Government primary health care facility & $4(11.1)$ & $15(10.2)$ & $19(10.4)$ & \multirow[t]{4}{*}{0.126} \\
\hline Government hospital & $31(86.1)$ & $105(71.4)$ & $136(74.3)$ & \\
\hline Faith based health center or hospital & $0(0.0)$ & $15(10.2)$ & $15(8.2)$ & \\
\hline Other & $1(2.8)$ & $12(8.2)$ & $13(7.1)$ & \\
\hline \multicolumn{5}{|l|}{ Mode of supervision for TB treatment: intensive phase } \\
\hline Hospitalized & $21(100.0)$ & $72(94.7)$ & $93(95.9)$ & \multirow[t]{3}{*}{0.562} \\
\hline Self-administered & $0(0.0)$ & $2(2.6)$ & $2(2.1)$ & \\
\hline Unknown & $0(0.0)$ & $2(2.6)$ & $2(2.1)$ & \\
\hline \multicolumn{5}{|l|}{ Mode of supervision for TB treatment: continuation phase } \\
\hline Hospitalized & $0(0.0)$ & $2(2.8)$ & $2(2.3)$ & \multirow[t]{5}{*}{0.609} \\
\hline Self-administered & $13(86.7)$ & $57(80.3)$ & $70(81.4)$ & \\
\hline Community-based DOT & $1(6.7)$ & $10(14.1)$ & $11(12.8)$ & \\
\hline Facility-based DOT & $1(6.7)$ & $1(1.4)$ & $2(2.3)$ & \\
\hline Unknown & $0(0.0)$ & $1(1.4)$ & $1(1.2)$ & \\
\hline \multicolumn{5}{|l|}{ Currently hospitalized } \\
\hline No & $15(41.7)$ & $73(49.7)$ & $88(48.1)$ & \multirow[t]{2}{*}{0.390} \\
\hline Yes & $21(58.3)$ & $74(50.3)$ & $95(51.9)$ & \\
\hline \multicolumn{5}{|l|}{ Previously hospitalized in the current phase } \\
\hline No & $30(83.3)$ & 117 (79.6) & $147(80.3)$ & \multirow[t]{2}{*}{0.613} \\
\hline Yes & $6(16.7)$ & $30(20.4)$ & $36(19.7)$ & \\
\hline
\end{tabular}


Table 2 Clinical information of patients who participated in the Solomon Islands national tuberculosis patient cost survey: 20172019 (Continued)

\begin{tabular}{|c|c|c|c|c|}
\hline Clinical characteristics & $\begin{array}{l}\text { Extra-pulmonary TB } \\
N=36 \\
\mathrm{n}(\%)\end{array}$ & $\begin{array}{l}\text { Pulmonary TB } \\
N=147 \\
\text { n (\%) }\end{array}$ & $\begin{array}{l}\text { All patients } \\
N=183 \\
\mathrm{n}(\%)\end{array}$ & $p$ value ${ }^{*}$ \\
\hline Number of days hospitalized in the current phase, $r$ & $41.6(33.6,49.5)$ & $43.6(39.6,47.7)$ & $43.2(39.7,46.8)$ & 0.647 \\
\hline
\end{tabular}

Abbreviations: DOT Directly observed therapy; DST Drug susceptibility testing; DS TB Drug susceptible TB; EPTB Extra pulmonary TB; PTB Pulmonary TB; TB

Tuberculosis. * $P$ values compare the proportions of patients with the characteristic of interest, in the pulmonary and extra-pulmonary groups

or PTB for coping mechanisms, social consequences, social support or receipt of vouchers.

\section{Discussion}

This survey identified that the cost of TB care is catastrophic for almost all TB-affected households in Solomon Islands $(92.3 \%$, or $82.0 \%$, adjusted) as the median cost of TB care was equivalent to 8.8 times the monthly household income. Only $5 \%$ of patients received social support during their TB care, only $2 \%$ of patients had health insurance and one in five used their savings, borrowed money, or sold their assets to cope with the economic burden of TB.

The global TB report published by WHO in 2020 provides an overview of the results of other TB patient cost surveys to compare to the results observed in Solomon Islands [19]. By July 2019, 17 countries had completed a national TB patient cost survey [19]. In these countries, the percentage of TB-affected households who experienced catastrophic costs ranged from 19\% (95\%CI: $15-$ $25 \%$ ) in Lesotho to $83 \%$ (95\%CI: 76-86) in Timor-Leste $[19,20]$. Overall, the pooled average of catastrophic costs was $49 \%$ (95\%CI: 34-63) [19]. The figure observed in Solomon Islands is higher than the figures reported in all of these countries.

The high proportion of direct non-medical costs in Solomon Islands ( $62.1 \%$ of all costs) was largely driven by nutritional supplements (corresponding to the largest group of non-medical costs, at $27.3 \%$ of all costs). A similar observation was made in the Timor-Leste national TB patient cost survey, and in other surveys [2022]. Malnutrition is a known risk factor for TB [10] and weight loss is a well-documented symptom of TB [23]. Therefore there may be some groups of patients who are malnourished or underweight at TB diagnosis who seek to use nutritional supplements to recover. However, it is not clear what nutritional supplements are being bought by $\mathrm{TB}$ patients, if they have been recommended by health care workers, or if there are other local beliefs about the effect of certain nutritional supplements on health. The proportion of patients who are malnourished or who are underweight at TB diagnosis is also unknown in the Solomon Islands context. These issues require further investigation.

Table 3 Mean number of working hours lost for tuberculosis care for patients and their households in the Solomon Islands national tuberculosis patient cost survey: 2017-2019

\begin{tabular}{|c|c|c|c|c|}
\hline Amount of lost time & $\begin{array}{l}\text { Extra-pulmonary TB } \\
N=36 \\
\text { Mean no. of hours }(95 \% \mathrm{Cl})\end{array}$ & $\begin{array}{l}\text { Pulmonary TB } \\
N=147 \\
\text { Mean no. of hours }(95 \% \mathrm{Cl})\end{array}$ & $\begin{array}{l}\text { All patients } \\
N=183 \\
\text { Mean no. of hours }(95 \% \mathrm{Cl})\end{array}$ & $p$ value \\
\hline \multicolumn{5}{|l|}{ For TB care for TB patients } \\
\hline Pre-disease & $6.8(2.0,11.5)$ & $7.3(3.7,11.0)$ & $7.2(4.2,10.2)$ & 0.875 \\
\hline Hospitalization & $463.7(295.7,631.7)$ & $292.3(221.2,363.3)$ & $326.0(260.0,392.0)$ & 0.041 \\
\hline Directly observed therapy & $3.4(-1.6,8.3)$ & $11.5(-0.4,23.5)$ & $9.9(0.3,19.6)$ & 0.508 \\
\hline Drug pick-up & $15.0(-2.6,32.7)$ & $8.2(6.0,10.3)$ & $9.5(5.7,13.3)$ & 0.152 \\
\hline Follow-up & $3.8(0.8,6.8)$ & $4.2(2.0,6.4)$ & $4.1(2.2,6.0)$ & 0.877 \\
\hline Total lost time & $490.7(320.6,660.9)$ & $321.0(248.6,393.4)$ & $354.4(287.3,421.4)$ & 0.047 \\
\hline \multicolumn{5}{|c|}{ For TB care for household members of TB patients* } \\
\hline Hospitalization & $103.2(-5.8,212.2)$ & $227.3(13.3,441.2)$ & $198.5(33.3,363.7)$ & 0.531 \\
\hline Directly observed therapy & $0.0(0.0,0.0)$ & $15.1(-7.0,37.3)$ & $12.4(-5.7,30.6)$ & 0.531 \\
\hline Drug pick-up & $28.5(-19.2,76.1)$ & $8.5(4.6,12.5)$ & $11.9(3.9,19.9)$ & 0.065 \\
\hline Follow-up & $1.2(-0.1,2.5)$ & $3.8(1.0,6.6)$ & $3.2(1.1,5.4)$ & 0.312 \\
\hline Total lost time & $63.4(9.6,117.2)$ & $117.6(25.6,209.5)$ & $105.7(33.1,178.3)$ & 0.544 \\
\hline
\end{tabular}

Abbreviations: Cl Confidence interval; no number; TB Tuberculosis.* This is in addition to the TB patient 
Table 4 Estimated median costs (USD) incurred by tuberculosis affected households in the Solomon Islands tuberculosis patient cost survey: 2017-2019

\begin{tabular}{|c|c|c|c|c|}
\hline Cost category & $\begin{array}{l}\text { Extra-pulmonary TB } \\
N=36 \\
\text { Median (IQR) in USD }\end{array}$ & $\begin{array}{l}\text { Pulmonary TB } \\
N=147 \\
\text { Median (IQR) in USD }\end{array}$ & $\begin{array}{l}\text { All patients } \\
N=183 \\
\text { Median (IQR) in USD }\end{array}$ & $p$ value \\
\hline \multicolumn{5}{|l|}{ Before TB diagnosis } \\
\hline Direct medical & $0(0,0)$ & $0(0,0)$ & $0(0,0)$ & 0.033 \\
\hline Direct non-medical & $6(5,10)$ & $6(4,6)$ & $6(4,6)$ & 0.577 \\
\hline Total direct before diagnosis & $6(5,10)$ & $6(4,6)$ & $6(5,6)$ & 0.706 \\
\hline \multicolumn{5}{|l|}{ During TB treatment: direct medical } \\
\hline Drug pickup & $0(0,0)$ & $0(0,0)$ & $0(0,0)$ & 0.776 \\
\hline Directly observed therapy & $0(0,0)$ & $0(0,0)$ & $0(0,0)$ & 0.675 \\
\hline Follow up & $0(0,0)$ & $0(0,0)$ & $0(0,0)$ & 0.843 \\
\hline Hospitalization & $58(0,75)$ & $33(0,62)$ & $36(0,68)$ & 0.181 \\
\hline Total direct medical during treatment & $58(0,76)$ & $36(0,69)$ & $37(0,71)$ & 0.260 \\
\hline \multicolumn{5}{|l|}{ During TB treatment: direct non-medical } \\
\hline Transportation & $76(65,167)$ & $30(10,107)$ & $46(13,123)$ & $<0.001$ \\
\hline Accommodation & $58(0,72)$ & $31(0,59)$ & $32(0,65)$ & 0.109 \\
\hline Food during visits & $75(59,160)$ & $49(11,134)$ & $64(15,142)$ & 0.039 \\
\hline Nutritional supplement & $320(0,880)$ & $64(0,427)$ & $85(0,427)$ & 0.097 \\
\hline Total direct non-medical & $501(212,1323)$ & $395(122,826)$ & $435(146,961)$ & 0.046 \\
\hline \multicolumn{5}{|l|}{ Total } \\
\hline Direct medical & $58(0,76)$ & $36(0,70)$ & $38(0,73)$ & 0.292 \\
\hline Direct non-medical & $509(218,1330)$ & $390(113,846)$ & $435(141,961)$ & 0.042 \\
\hline Total direct & $630(271,1390)$ & $486(165,989)$ & $494(189,1110)$ & 0.044 \\
\hline Income loss & $99(0,258)$ & $74(0,333)$ & $74(0,296)$ & 0.500 \\
\hline Grand total & $779(427,2302)$ & $693(343,1207)$ & $716(349,1247)$ & 0.107 \\
\hline
\end{tabular}

Abbreviations: IQR Inter quartile range; EPTB Extra pulmonary TB; PTB Pulmonary TB; USD United States Dollars; TB Tuberculosis

Travel, food and accommodation costs were also considerable, accounting for $32.3 \%$ of all costs, which may be attributable to the fact that the people travel (often long distances) to get to one of the DOTS centres for a TB diagnosis. TB care is offered in one DOTS centre per province and the country is very geographically dispersed. Therefore patients and their families may travel long distances from their home village to the nearest DOTS centre to seek a TB diagnosis. If they are diagnosed, then the current national policy is that they are hospitalised for the first two months of TB care (i.e. the intensive phase). This is reflected in our results where approximately half (51.9\%) of patients were hospitalised at the time of interview and one in five patients (19.7\%) had been previously hospitalised. The Ministry of Health and Medical Services is currently considering options to introduce community based and ambulatory treatment.

Income loss accounted for $28.5 \%$ of all costs and $8.2 \%$ of people lost their job while receiving TB care. Loss of employment and income loss are major barriers faced by many TB patients, $[22,24,25]$ with the stigma around $\mathrm{TB}$ and misunderstandings about infectiousness as potential contributing factors. These income losses can be compensated for by social or financial protection schemes in many countries. However, these kinds of schemes are generally not available in the Solomon Islands. Voluntary health insurance is also generally not available with the exception of schemes for expatriates [15].

\section{Strengths and limitations}

This is the first survey on the costs associated with TB diagnosis and care in Solomon Islands. The survey provided baseline information including information on health seeking behaviour, the costs of health care and the drivers of these costs; these data can be used for further monitoring of the End TB Strategy indicator and for national planning. The survey investigators also demonstrated that collecting data using online tools is feasible in the Solomon Islands context and data completeness was attained for many variables. In addition, the survey is nationally representative, including all ten DOTS centres, which is not always easy in geographically dispersed countries such as the Solomon Islands. 


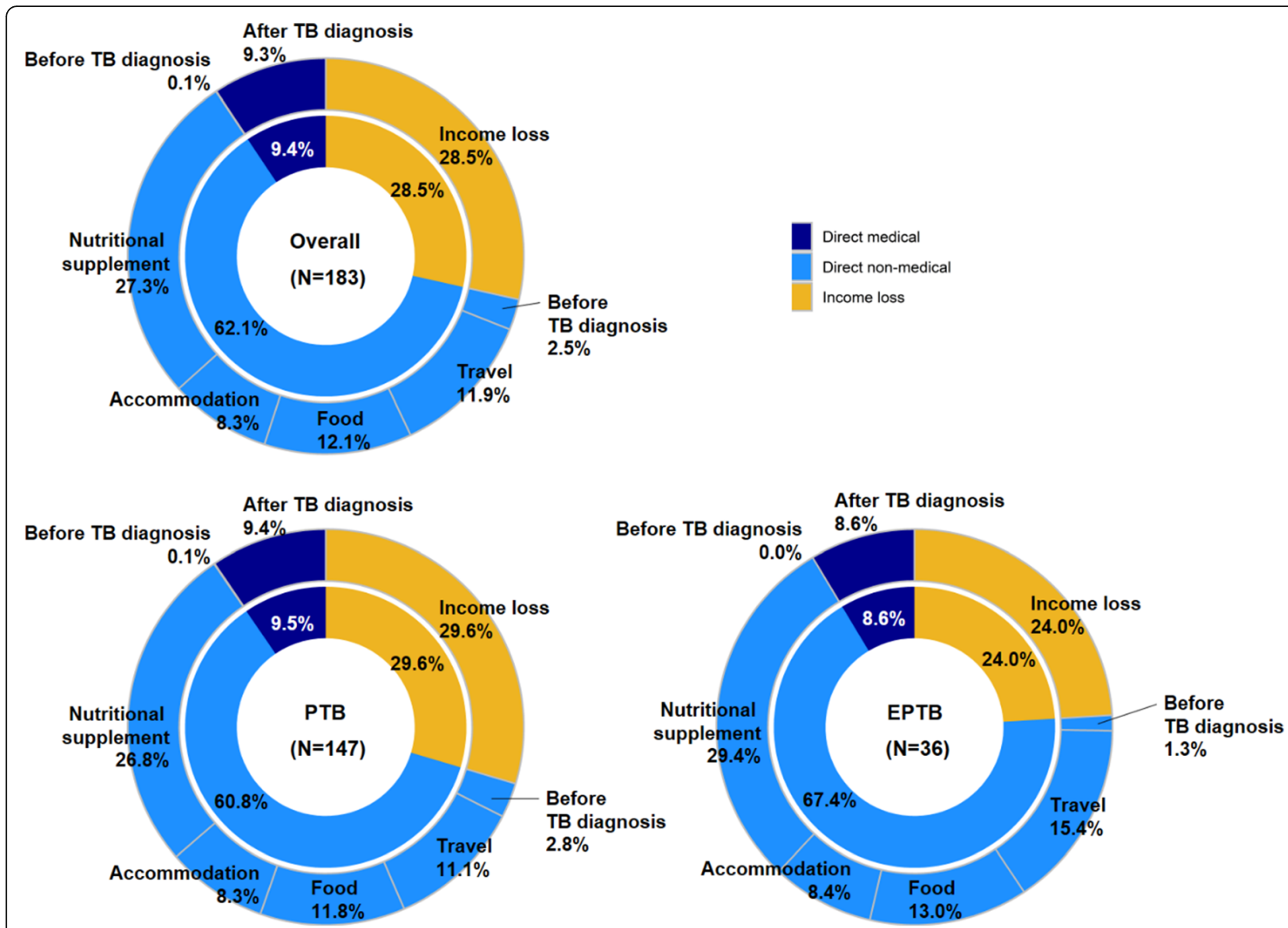

Fig. 1 Categories of costs as a proportion of all costs associated with a tuberculosis diagnosis and care from the Solomon Islands national tuberculosis patient cost survey: 2017-2019 (based on mean values)

This survey also has some limitations. First, the survey investigators originally intended to recruit patients from April to November 2016 and had developed a sampling strategy that included a representative sample from all provinces in the Solomon Islands, whereas, in practice, the period of recruitment ran over three years (20172019). However, a comparison of some of the key demographic characteristics in the sample was undertaken and these were compared to the 2018 national TB surveillance data. There were no statistically significant differences in these variables when comparing the two populations (T. Yamanaka, personal communication, 2020). Second, this was a cross-sectional survey with forward extrapolations on patient costs. While this is a practical method given the context of the study and is recommended by WHO, the estimated costs may not reflect the true costs experiences by the patients due to the illness. Longitudinal methods of determining patient costs are accurate but may be more accurate. Third, recall bias is a concern when recalling costs incurred in the past. As much as possible the interviewers used prompts to assist patients in recalling costs, but it is possible that the recollected numbers may have been inaccurate. Fourth, the survey did not reach the estimated sample size, but it was planned on notifications in previous years and then there were relatively small numbers of patients in the participating DOTS centres, a common challenge in countries with a lower TB case load and where the number of TB patients may fluctuate over time. As well, we recalculated the sample size based on our finding that the proportion of patients with catastrophic costs in Solomon Islands was 92.3\%. Using this figure and the other sample size parameters described in our Methods section, we would have required a sample size of $126 \mathrm{~TB}$ patients. Therefore our sample size of $183 \mathrm{~TB}$ patients was sufficient even though it fell short of our original estimated sample size. Then, we used an estimate of $30 \%$ of catastrophic costs to estimate our sample size, which was an under estimate. However using a higher estimate would have resulted in a smaller sample size, so we did not under sample in our study and as more catastrophic cost surveys have been conducted now it may be more feasible to provide an estimate of the patients with catastrophic costs. Lastly, self- 
Table 5 Risk factors associated with catastrophic costs due to tuberculosis from the Solomon Islands national tuberculosis patient cost survey: 2017-2019

\begin{tabular}{|c|c|c|c|c|c|}
\hline Variable and categories & & $\mathbf{N}$ & n (\%) & $\begin{array}{l}\text { Crude OR } \\
\text { (95\% Cl, } p \text {-value) }\end{array}$ & $\begin{array}{l}\text { Adjusted OR } \\
\text { (95\% Cl, } p \text {-value) }\end{array}$ \\
\hline \multirow[t]{6}{*}{ Age group (years) } & $0-14$ & 21 & $16(76.2)$ & Referent & - \\
\hline & $15-24$ & 41 & $34(82.9)$ & $1.52(0.40-5.52, p=0.527)$ & $1.80(0.21-15.57, p=0.587)$ \\
\hline & $25-34$ & 40 & $30(75.0)$ & $0.94(0.26-3.14, p=0.918)$ & $1.04(0.15-6.89, p=0.966)$ \\
\hline & $35-44$ & 38 & $31(81.6)$ & $1.38(0.36-5.05, p=0.623)$ & $1.04(0.15-6.83, p=0.964)$ \\
\hline & $45-54$ & 24 & $22(91.7)$ & $3.44(0.65-26.19, p=0.170)$ & $1.59(0.16-19.20, p=0.694)$ \\
\hline & $55+$ & 19 & $17(89.5)$ & $2.66(0.49-20.44, p=0.281)$ & $0.79(0.08-8.97, p=0.839)$ \\
\hline \multirow[t]{2}{*}{ Sex } & Female & 91 & $73(80.2)$ & Referent & - \\
\hline & Male & 92 & 77 (83.7) & $1.27(0.59-2.73, p=0.541)$ & $2.81(0.91-9.59, p=0.082)$ \\
\hline \multirow[t]{2}{*}{ Type of disease } & EPTB & 36 & $31(86.1)$ & Referent & - \\
\hline & PTB & 147 & $\begin{array}{l}119 \\
(81.0)\end{array}$ & $0.69(0.22-1.79, p=0.473)$ & $0.41(0.08-1.69, p=0.241)$ \\
\hline \multirow[t]{3}{*}{ Income quintile } & Wealthiest & 48 & $21(43.8)$ & Referent & - \\
\hline & Fourth & 38 & $35(92.1)$ & $15.00(4.60-68.37, p<0.001)$ & $17.66(4.81-94.42, p<0.001)$ \\
\hline & Poorest, second or third & 97 & $94(96.9)$ & $\begin{array}{l}40.29(12.77-180.20, p< \\
0.001)\end{array}$ & $\begin{array}{l}67.25(15.86-489.74, p< \\
0.001)\end{array}$ \\
\hline \multirow{2}{*}{$\begin{array}{l}\text { Household size (no. of } \\
\text { persons) }\end{array}$} & $0-7$ & 91 & $75(82.4)$ & Referent & - \\
\hline & 8 or more & 92 & $75(81.5)$ & $0.94(0.44-2.01, p=0.875)$ & - \\
\hline \multirow[t]{3}{*}{ Education level } & University, vocational or other & 10 & $6(60.0)$ & Referent & - \\
\hline & Secondary school & 49 & $35(71.4)$ & $1.67(0.38-6.77, p=0.477)$ & $2.37(0.30-19.05, p=0.408)$ \\
\hline & $\begin{array}{l}\text { No education, pre-school, or primary } \\
\text { school }\end{array}$ & 123 & $\begin{array}{l}109 \\
(88.6)\end{array}$ & $5.19(1.21-20.55, p=0.020)$ & $5.18(0.69-38.16, p=0.102)$ \\
\hline \multirow[t]{4}{*}{ Type of health facility } & Government primary health care facility & 19 & $17(89.5)$ & Referent & - \\
\hline & Government hospital & 136 & $\begin{array}{l}108 \\
(79.4)\end{array}$ & $0.45(0.07-1.71, p=0.309)$ & - \\
\hline & Faith based health center or hospital & 15 & $13(86.7)$ & $0.76(0.08-7.07, p=0.801)$ & - \\
\hline & Other & 13 & $12(92.3)$ & $1.41(0.12-32.44, p=0.788)$ & - \\
\hline \multirow[t]{2}{*}{ TB treatment phase } & Intensive phase & 97 & $83(85.6)$ & Referent & - \\
\hline & Continuation phase & 86 & $67(77.9)$ & $0.59(0.27-1.27, p=0.181)$ & $0.27(0.02-4.05, p=0.319)$ \\
\hline \multirow[t]{2}{*}{ Hospitalized in current phase } & No & 147 & $\begin{array}{l}122 \\
(83.0)\end{array}$ & Referent & - \\
\hline & Yes & 36 & $28(77.8)$ & $0.72(0.30-1.85, p=0.467)$ & - \\
\hline \multirow{2}{*}{$\begin{array}{l}\text { Hospitalized at time of } \\
\text { interview }\end{array}$} & No & 88 & $68(77.3)$ & Referent & - \\
\hline & Yes & 95 & $82(86.3)$ & $1.86(0.87-4.08, p=0.115)$ & $0.70(0.05-10.76, p=0.783)$ \\
\hline \multirow[t]{2}{*}{ Delay before diagnosis } & No & 39 & $35(89.7)$ & Referent & - \\
\hline & Yes & 44 & $37(84.1)$ & $0.60(0.15-2.18, p=0.452)$ & - \\
\hline
\end{tabular}

Abbreviations: $\mathrm{Cl}$ Confidence interval; $O R$ Odds ratio

reported income was used as the measure of income in this survey. Other methods of reporting or estimating income - such as household consumption/ expenditure may be more accurate in settings such as Solomon Islands where the majority of the population are employed in the informal employment sector. Therefore, the proportion of patients with catastrophic costs may have been overestimated in this survey, which is consistent with the fact that only $11.5 \%$ of people thought that
TB had a very severe financial impact on them. Future methodological work on measuring income may determine which approach is preferred [26].

\section{Public health implications}

The findings from this survey highlight some of the difficulties that patients in Solomon Islands experience when accessing TB care. These findings are informative for policy makers as they consider how they can improve 
Table 6 Coping mechanisms, social consequences, perceived financial impact and social support reported by patients who participated in the Solomon Islands tuberculosis patient cost survey: 2017-2019

\begin{tabular}{|c|c|c|c|c|}
\hline Category & $\begin{array}{l}\text { Extra-pulmonary TB } \\
N=36(\%) \\
\mathrm{n}(\%)\end{array}$ & $\begin{array}{l}\text { Pulmonary TB } \\
N=147 \\
\mathrm{n}(\%)\end{array}$ & $\begin{array}{l}\text { All patients } \\
N=183 \\
\mathrm{n}(\%)\end{array}$ & $p$ value \\
\hline \multicolumn{5}{|l|}{ Coping mechanisms } \\
\hline Dissavings & $2(5.6)$ & $15(10.2)$ & $17(9.3)$ & 0.389 \\
\hline Took out a loan & $3(8.3)$ & 17 (11.6) & $20(10.9)$ & 0.578 \\
\hline Sold assets & $0(0.0)$ & $6(4.1)$ & $6(3.3)$ & 0.218 \\
\hline Any of the above & $5(13.9)$ & $31(21.1)$ & $36(19.7)$ & 0.330 \\
\hline \multicolumn{5}{|l|}{ Social consequences } \\
\hline Social exclusion & $2(5.6)$ & $12(8.2)$ & $14(7.7)$ & 0.598 \\
\hline Food insecurity & $7(19.4)$ & $38(25.9)$ & 45 (24.6) & 0.424 \\
\hline Job loss & $5(13.9)$ & $10(6.8)$ & $15(8.2)$ & 0.165 \\
\hline Interrupted schooling & $7(19.4)$ & $32(21.8)$ & $39(21.3)$ & 0.760 \\
\hline Divorce & $0(0.0)$ & $1(0.7)$ & $1(0.5)$ & 0.620 \\
\hline Any of the above & $20(55.6)$ & 79 (53.7) & $99(54.1)$ & 0.845 \\
\hline \multicolumn{5}{|l|}{ Perceived financial impact } \\
\hline No impact & $1(2.8)$ & $0(0.0)$ & $1(0.5)$ & 0.205 \\
\hline Little impact & $3(8.3)$ & $26(17.7)$ & $29(15.8)$ & \\
\hline Moderate impact & $14(38.9)$ & $54(36.7)$ & $68(37.2)$ & \\
\hline Serious impact & $14(38.9)$ & $50(34.0)$ & $64(35.0)$ & \\
\hline Very serious impact & $4(11.1)$ & $17(11.6)$ & $21(11.5)$ & \\
\hline \multicolumn{5}{|l|}{ Social support } \\
\hline From family or relatives & $1(50.0)$ & $6(85.7)$ & $7(77.8)$ & 0.284 \\
\hline From a Member of Parliament & $1(50.0)$ & $1(14.3)$ & $2(22.2)$ & \\
\hline Total (proportion of all patients) & $2(5.6 \%)$ & $7(4.8)$ & $9(4.9)$ & 0.844 \\
\hline \multicolumn{5}{|l|}{ Receipt of vouchers } \\
\hline Food support & $16(100.0)$ & $47(94.0)$ & $63(95.5)$ & 0.605 \\
\hline Travel voucher & $0(0)$ & $1(2.0)$ & $1(1.5)$ & \\
\hline Unknown type & $0(0)$ & $2(4.0)$ & $2(3.0)$ & \\
\hline Total (proportion of all patients) & $16(44.4)$ & $50(34.0)$ & $66(36.1)$ & 0.243 \\
\hline
\end{tabular}

Abbreviation: TB Tuberculosis

and expand universal health coverage in the Solomon Islands. One obvious policy relevant finding is the cost of accessing TB care in Solomon Islands and the need to mitigate these costs of care, where possible. Mitigation strategies may include the provision of vouchers or subsidies for TB patients that could be provided by the NTLP in the absence of wider social or financial protection schemes, which are currently limited in the Solomon Islands [27]. Recently, the Solomon Islands Government has adopted universal health coverage as the principle of health system design and a role delineation policy is the major vehicle to achieve it [11]. This policy defines a service delivery package and ensures minimum services at the lowest level of health services close to the community [11]. In the years to come, universal health coverage rollout in Solomon Islands may help to mitigate patient costs. A small financial incentive has been part of the Global Fund TB grant in the Solomon Islands for a number of years. However, there have been problems with operationalising this scheme and it may now be timely to revisit the reasons for this and propose a workable solution. The cost of TB care also has an impact on families and given the system of family responsibility in Solomon Islands as part of the wantok system, [28] a kinship network where caring for one's relatives is extremely important, the impact of $\mathrm{TB}$ on families (especially poor ones) should be recognised. In addition, over the longer term any social or financial protection schemes should be inclusive of TB patients and future models of $\mathrm{TB}$ care should recognise the costs of care as a factor in their planning. 


\section{Conclusion}

Tuberculosis is a financially disabling condition in Solomon Islands. Non-medical costs and loss of income are the main cost drivers. TB patients had very little access to social or financial protection and not being in the wealthiest wealth quintile was associated with catastrophic costs. In the longer term access to social and financial protection may protect patients against the costs of TB care. However, in the shorter term the NTLP may want to consider the provision of vouchers to TB patients and their families while longer term measures such as the advancement of universal health coverage and other social and financial protection measures are pursued.

\section{Abbreviations \\ DOTS: Directly Observed Teatment Short-course; EPTB: Extra pulmonary tuberculosis; HIES : Household Income and Expenditure Survey; IQR: Inter quartile range; NTLP: National tuberculosis and leprosy programme; PTB : Pulmonary tuberculosis; TB: Tuberculosis; USD: United States dollars; WHO: World Health Organization}

\section{Supplementary Information}

The online version contains supplementary material available at https://doi. org/10.1186/s12889-021-11938-8.

Additional file 1. National TB patient cost survey questionnaire for the Solomon Islands.

Additional file 2: Table S1. Household income by type of income and by decile in the Solomon Islands Household Income and Expenditure Survey, 2013 (in Solomon Islands dollars). Table S2. Mean number of facility visits and diagnostic delay for participants in the Solomon Islands national tuberculosis patient cost survey: 2017-2019. Table S3.

Tuberculosis affected households classified as facing catastrophic costs by different thresholds, from the Solomon Islands national tuberculosis patient cost survey: 2017-2019. Table S4. Re-classification of tuberculosis-affected households into income decile based on the 2013 Solomon Islands Household Income and Expenditure Survey. Table S5. Estimated median total costs (USD) incurred with adjusted household income from the Solomon Islands national tuberculosis patient cost survey: 2017-2019.

\section{Acknowledgements}

We would like to acknowledge and thank a number of people and organisations who made contributions to this survey. First, we acknowledge the large contribution of the interviewers and National TB and Leprosy Control Programme staff who collected the data and who managed all aspects of the implementation of the survey (including the Provincial TB Coordinators who were the interviewers). We would like to thank the 183 TB patients for being willing to give up their time to be interviewed and for providing information on their personal circumstances.

\section{Authors' contributions}

KV and SVN submitted an initial funding application for the study. KV, SVN, $\mathrm{NI}$ and $\mathrm{NN}$ conceived the study. NI, KV, SVN, RJ and NN designed the study. $\mathrm{NI}, \mathrm{KV}, \mathrm{SVN}, \mathrm{RJ}, \mathrm{FM}, \mathrm{AH}$ and TY were involved in the implementation of the study, which was led by NI and the Solomon Islands NTLP. TY analysed the data. All authors interpreted the data. KV drafted the manuscript. All authors read, critically revised and approved the final manuscript. The authors alone are responsible for the views expressed in this article and they do not necessarily represent the views, decisions or policies of the institutions with which they are affiliated.

\section{Funding}

Funding for this survey was provided by the Solomon Islands Ministry of Health and Medical Services, the Research School of Population Health, Australian National University (Excellence in Population Health Award) and the World Health Organization. One of the lead investigators for this study (Dr Kerri Viney) was supported by a Sidney Sax Early Career Fellowship Grant from the National Health and Medical Research Council (GNT1121611).

\section{Availability of data and materials}

The datasets used and/or analysed during the current study are available from the corresponding author on reasonable request, and following approval by the Solomon Islands Ministry of Health and Medical Services, who are the custodians of the data. The questionnaire was developed by the Global Tuberculosis Programme, World Health Organization and we have permission to publish it.

\section{Declarations}

Ethics approval and consent to participate

Ethical approval for the survey was provided by the Australian National University Human Research Ethics Committee (2016/110) and the Solomon Islands National Health Research Ethics Committee, Ministry of Health and Medical Services (HRE007/16). Written informed consent or assent was obtained from all participants (written informed consent from the patient if aged 18 years and above, or from the parent or guardian for children aged 0-17 years, and written informed assent for children aged between 7 and 17 years, when accompanied by a parent or guardian). Patients were not offered any incentives to participate.

\section{Consent for publication}

Not applicable.

\section{Competing interests}

The authors declare that they have no competing interests.

\section{Author details}

${ }^{1}$ Research School of Population Health, Australian National University, Canberra, Australia. ${ }^{2}$ Global TB Programme, World Health Organization Headquarters, Geneva, Switzerland. '3 Department of Global Public Health, Karolinska Institutet, Stockholm, Sweden. ${ }^{4}$ National TB Programme, Ministry of Health and Medical Services, Honiara, Solomon Islands. ${ }^{5}$ World Health Organization Country Office, Honiara, Solomon Islands. ${ }^{6}$ Department of Global Health and Development, London School of Hygiene \& Tropical Medicine, London, UK. ${ }^{7}$ School of Tropical Medicine \& Global Health, Nagasaki University, Nagasaki, Japan. ${ }^{8}$ Independent consultant, Tunis, Tunisia. ${ }^{9}$ End TB and Leprosy Unit, World Health Organization Regional Office of the Western Pacific, Manila, Philippines. ${ }^{10}$ The Kirby Institute, University of New South Wales Sydney, Sydney, Australia.

Received: 8 October 2020 Accepted: 7 October 2021

Published online: 23 October 2021

\section{References}

1. World Health Organization. Implementing the End TB Strategy: The essentials. Geneva: World Health Organization; 2015.

2. Tanimura T, Jaramillo E, Weil D, Raviglione M, Lönnroth K. Financial burden for tuberculosis patients in low-and middle-income countries: a systematic review. Eur Respir J. 2014;43(6):1763-75. https://doi.org/10.1183/09031936. 00193413.

3. Barter D, Agboola S, Murray M, Barnighausen T. Tuberculosis and poverty: the contribution of patient costs in sub-Saharan Africa- a systematic review. BMC Public Health. 2012;12(980):1-34. https://doi.org/10.1186/1471-2458-12980.

4. Mauch V, Bonsu F, Gyapong M, Awini E, Suarez P, Marcelino B, et al. Free tuberculosis diagnosis and treatment are not enough: patient cost evidence from three continents. Int J Tuberc Lung Dis. 2013;17(3):381-7. https://doi. org/10.5588/ijtld.12.0368.

5. Kemp JR, Mann G, Simwaka BN, Salaniponi FM, Squire SB. Can Malawi's poor afford free tuberculosis services? Patient and household costs associated with a tuberculosis diagnosis in Lilongwe. Bull World Health Organ. 2007; 85(8):580-5. https://doi.org/10.2471/BLT.06.033167. 
6. Foster N, Vassall A, Cleary S, Cunnama L, Churchyard G, Sinanovic E. The economic burden of TB diagnosis and treatment in South Africa. Soc Sc Med. 2015;130:42-50. https://doi.org/10.1016/j.socscimed.2015.01.046.

7. World Health Organization. Tuberculosis patient cost surveys: A handbook. Geneva: World Health Organization; 2017.

8. World Health Organization. Protocol for survey to determine direct and indirect costs due to TB and to estimate proportion of TB-affected households experiencing catastrophic costs: field testing version. Geneva: World Health Organization; 2015.

9. The World Bank. World Bank country and lending groups. Washington D.C: The World Bank; 2020. [cited 202018 May]. Available from: https://data helpdesk.worldbank.org/knowledgebase/articles/906519-world-bankcountry-and-lending-groups.

10. World Health Organization. Global Tuberculosis Report 2019. Geneva: World Health Organization; 2019.

11. Solomon Islands Ministry of Health and Medical Services. Review of the national tuberculosis program of Solomon Islands Honiara, Solomon Islands Solomon Islands Ministry of Health and Medical Services; 2019.

12. United Nations Office for the Coordination of Humanitarian Affairs. Solomon Islands New York, United States of America: United Nations Office for the Coordination of Humanitarian Affairs; 2018. [cited 202018 May]. Available from: https://www.unocha.org/office-pacific-islands/solomon-islands.

13. Solomon Islands National Statistics Office. Population. Projected population by province 2010-2025 Honiara. Solomon Islands: Solomon Islands National Statistics Office; 2020. [cited 202027 July ]. Available from: https://www.sta tistics.gov.sb/statistics/social-statistics/population.

14. Solomon Islands National Statistics Office. Solomon Islands poverty profile based on the 2012/13 household income and expenditure survey. Honiara: Solomon Islands National Statistics Office; 2015.

15. Hodge N, Slatyer B, Skiller L. Solomon Islands health system review Whittaker M, editor. Manila: Philippines World Health Organization; 2015.

16. World Health Organization Regional Office of the Western Pacific. UHC and SDG country profile 2018 Solomon islands. Manila: World Health Organization Regional Office of the Western Pacific; 2018.

17. Negin J, Martiniuk AL, Farrell P, Dalipanda T. Frequency, cost and impact of inter-island referrals in the Solomon Islands. Rural and Remote Health. 2012; 12(2096):Online

18. Solomon Islands National Statistics Office. Solomon Islands Household Income and Expenditure Survey National Analytical Tables. Honiara: Solomon Islands National Statistics Office, Ministry of Finance and Treasury; 2015.

19. World Health Organization. Global tuberculosis report 2020. Geneva: World Health Organization; 2020.

20. Viney K, Amaral S, Marques EB, Siroka A, Lopes C, Nery SV. Four of five tuberculosis patients experience catastrophic costs related to TB diagnosis and care in Timor-Leste. Int J Tuberc Lung Dis. 2019;23(11):1191-7. https:// doi.org/10.5588/ijtld.18.0765.

21. Pedrazzoli D, Siroka A, Boccia D, Bonsu F, Nartey K, Houben R, et al. How affordable is TB care? Findings from a nationwide TB patient cost survey in Ghana. Tropical Med Int Health. 2018;23(8):870-8. https://doi.org/10.1111/tmi.13085.

22. Nhung NV, Hoa NB, Anh NT, Anh LTN, Siroka A, Lonnroth K, et al. Measuring catastrophic costs due to tuberculosis in Viet Nam. Int J Tuberc Lung Dis. 2018;22(9):983-90. https://doi.org/10.5588/ijtld.17.0859. Epub 2018/08/11. PubMed PMID: 30092862

23. Pai M, Behr MA, Dowdy D, Dheda K, Divangahi M, Boehme CC, et al. Tuberculosis. Nat Rev Dis Primers. 2016:2(Article number: 16076):1-23.

24. Stracker N, Hanrahan C, Mmolawa L, Nonyane B, Tampi R, Tucker A, et al. Risk factors for catastrophic costs associated with tuberculosis in rural South Africa. Int J Tuberc Lung Dis. 2019;23(6):756-63. https://doi.org/10.5588/ijtld.18.0519.

25. Collins D, Beyene D, Tedla Y, Mesfin H, Diro E. Can patients afford the cost of treatment for multidrug-resistant tuberculosis in Ethiopia? Int I Tuberc Lung Dis. 2018;22(8):905-11.

26. Sweeney S, Mukora R, Candfield S, Guinness L, Grant AD, Vassall A. Measuring income for catastrophic cost estimates: limitations and policy implications of current approaches. Soc Sci Med. 2018;215:7-15. https://doi. org/10.1016/j.socscimed.2018.08.041.

27. Boccia D, Hargreaves J, Lönnroth K, Jaramillo E, Weiss J, Uplekar M, et al. Cash transfer and microfinance interventions for tuberculosis control: review of the impact evidence and policy implications. Int J Tuberc Lung Dis. 2011; 15(6):S37-49.

28. Nanau GL. The wantok system as a socio-economic and political network in Melanesia. J Multicultural Soc. 2011;2(1):31-55.

\section{Publisher's Note}

Springer Nature remains neutral with regard to jurisdictional claims in published maps and institutional affiliations.
Ready to submit your research? Choose BMC and benefit from:

- fast, convenient online submission

- thorough peer review by experienced researchers in your field

- rapid publication on acceptance

- support for research data, including large and complex data types

- gold Open Access which fosters wider collaboration and increased citations

- maximum visibility for your research: over $100 \mathrm{M}$ website views per year

At BMC, research is always in progress.

Learn more biomedcentral.com/submissions 